\title{
Synthesis, Construction, and Evaluation of Self-Assembled Nano-Bacitracin $a$ as an Efficient Antibacterial Agent in vitro and in vivo [Corrigendum]
}

Hong W, Gao X, Qiu P, et al. Int J Nanomedicine. 2017;12:4691-4708.

The authors have advised due to an operator error Figure 4 on page 4700 is incorrect. The correct Figure 4 is shown below. negative control group instead of BA solution. The correct Figure 6 is shown below.

The authors apologize for these errors and advise they do not affect the results of the paper.

The authors have also advised due to an error at the time of figure assembly, Figure 6B on page 4703 belongs to the

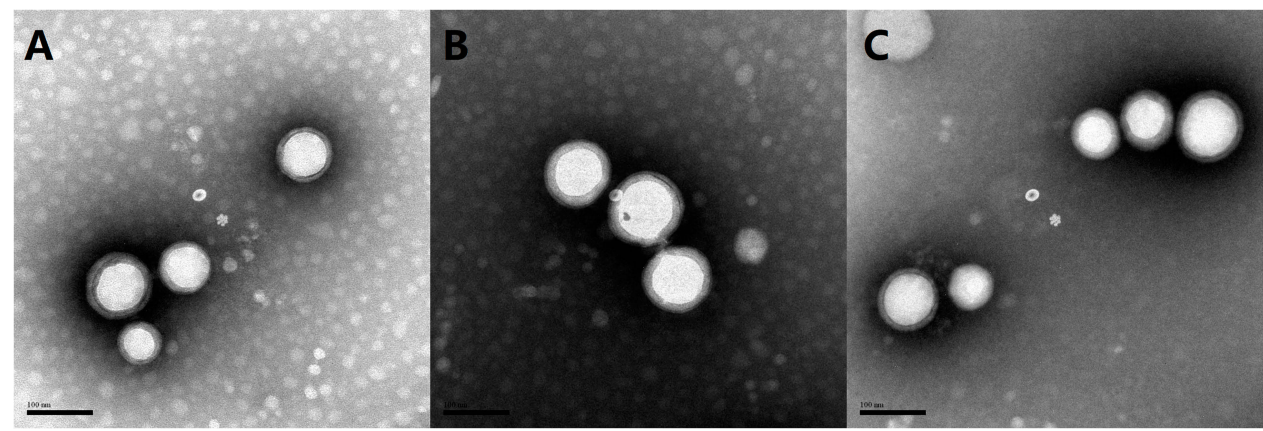

Figure 4 TEM images, particle size, and distribution of $\mathrm{Nano}^{-\mathrm{BA}_{3 \mathrm{~K}}(\mathbf{A}) \text {, Nano-BA }} \mathrm{AK}_{5 \mathrm{~K}}(\mathbf{B})$, and $\mathrm{Nano}-\mathrm{BA}_{8 \mathrm{KK}}(\mathbf{C})$ at $\mathrm{pH} 7.4$. Abbreviation: TEM, transmission electron microscopy.
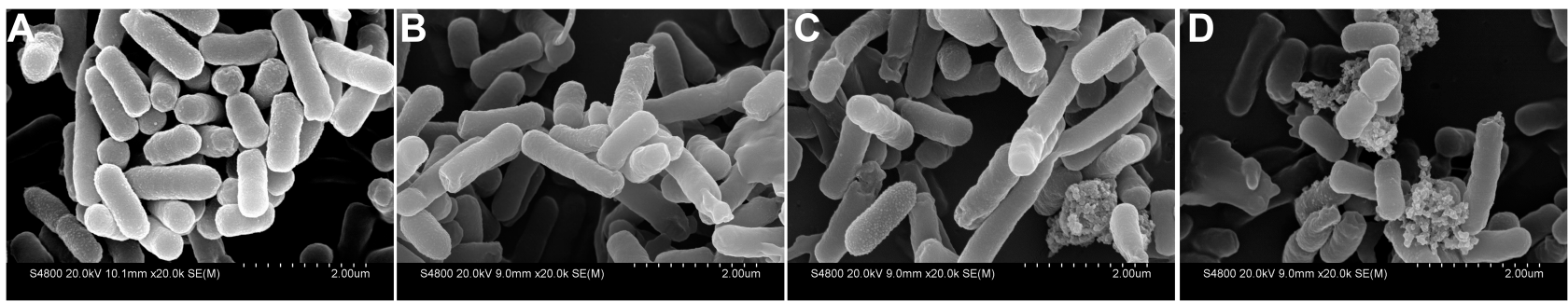

Figure 6 SEM micrographs of E. coli ATCC 25922 treated by negative control (A), BA solution (B), Nano-BA ${ }_{5 K}$ (C), and polymyxin B (D) for $2 \mathrm{~h}$. Abbreviations: SEM, scanning electron microscopy; BA, bacitracin A; E. coli, Escherichia coli; ATCC, American Type Culture Collection.

\section{Publish your work in this journal}

The International Journal of Nanomedicine is an international, peerreviewed journal focusing on the application of nanotechnology in diagnostics, therapeutics, and drug delivery systems throughout the biomedical field. This journal is indexed on PubMed Central, MedLine, CAS, SciSearch ${ }^{\mathbb{B}}$, Current Contents ${ }^{\mathbb{B}} /$ Clinical Medicine,
Journal Citation Reports/Science Edition, EMBase, Scopus and the Elsevier Bibliographic databases. The manuscript management system is completely online and includes a very quick and fair peer-review system, which is all easy to use. Visit http://www.dovepress.com/ testimonials.php to read real quotes from published authors. 